\title{
Pollution pathways and release estimation of perfluorooctane sulfonate (PFOS) and perfluorooctanoic acid (PFOA) in central and eastern China
}

\author{
Zhaoyang Liu ${ }^{\mathrm{a}, \mathrm{b}}$, Yonglong Lu ${ }^{\mathrm{a}, *}$, Pei Wang ${ }^{\mathrm{a}}$, Tieyu Wang ${ }^{\mathrm{a}}$, Shijie Liu ${ }^{\mathrm{c}}$, Andrew C. Johnson ${ }^{\mathrm{d}}$, \\ Andrew J. Sweetman ${ }^{\mathrm{d}, \mathrm{e}}$, Yvette Baninla ${ }^{\mathrm{a}, \mathrm{b}}$ \\ a State Key Laboratory of Urban and Regional Ecology, Research Center for Eco-Environmental Sciences, Chinese Academy of Sciences, Beijing 100085, China \\ b University of Chinese Academy of Sciences, Beijing 100049, China \\ c State Key Laboratory of Environmental Criteria and Risk Assessment, Chinese Research Academy of Environmental Sciences, Beijing 100012, China \\ d Centre for Ecology \& Hydrology, Maclean Building, Crowmarsh Gifford Wallingford, Oxon OX10 8BB, UK \\ e Lancaster Environment Centre, Lancaster University, Lancaster LA1 4YQ UK
}

\section{H I G H L I G H T S}

- Pollution release and pathways of PFOS/ PFOA in multiple media are studied in China.

- Emission data and transport parameters are used for PFOS/PFOA release estimation.

- $70-80 \%$ of PFOS/PFOA in the Chinese environment comes from industrial wastewater.

- For PFOS the next most important pollution sources are use of AFFF and pesticides.

- For PFOA other main sources include air emission, domestic wastewater and landfill.

\section{A R T I C L E I N F O}

\section{Article history:}

Received 22 September 2016

Received in revised form 13 December 2016

Accepted 13 December 2016

Available online 28 December 2016

Editor: Adrian Covaci

\section{Keywords:}

PFOS

PFOA

Major sources

Transport pathway

Environmental release

Environmental risk

\footnotetext{
* Corresponding author.

E-mail address: yllu@rcees.ac.cn (Y. Lu).
}

GRAPH ICALABSTRACT

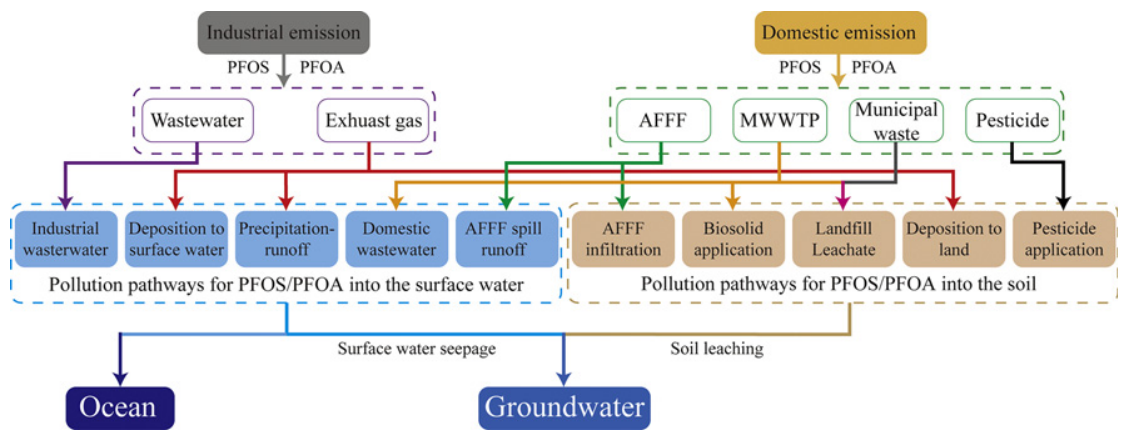

\section{A B S T R A C T}

China has gradually become the most important manufacturing and consumption centre for perfluorooctane sulfonate (PFOS) and perfluorooctanoic acid (PFOA) in the world, and inadvertently become the world's major contamination hotspots. However, a systematic analysis of pollution pathways for PFOS/PFOA into the different environmental compartments and their quantification in China has yet to be carried out. This study focused on PFOS and PFOA release into the environment in the central and eastern region of China, which accounts for the vast majority of national emission. About $80-90 \%$ of PFOS/PFOA contamination in the Chinese environment was estimated to come directly from manufacturing and industrial sites mostly via wastewater discharge from these facilities. The other major contamination sources for PFOS were identified as being linked to aqueous fire-fighting foams (AFFFs), and pesticides including sulfluramid. For PFOA, following some way behind industrial wastewater, were industrial exhaust gas, domestic wastewater and landfill leachate as contamination sources. For surface water contamination, the major pollution contributors after industrial wastewater were AFFF spill runoff for PFOS, and domestic wastewater and precipitation-runoff for PFOA. The majority of PFOS that contaminated soil was considered to be linked with infiltration of AFFF and pesticides, while most PFOA in soil was attributed to atmospheric deposition and landfill leachate. Where groundwater had become contaminated, surface water seepage was estimated to contribute about $50 \%$ of PFOS and $40 \%$ of PFOA while the remainder was mostly derived from soil leaching. A review of the available monitoring data for PFOS/PFOA in the literature 
supported the view that industrial wastewater, landfill leachate and AFFF application were the dominant sources. Higher concentrations of PFOA than PFOS found in precipitation also corroborated the prediction of more PFOA release into air. To reduce PFOS/PFOA contamination of the Chinese environment the focus for control should be on industrial wastewater emissions.

(c) 2016 Elsevier B.V. All rights reserved.

\section{Introduction}

Having excellent chemical stability, high surface activity, with water and oil repellence (Giesy and Kannan, 2001, 2002), perfluoroalkyl acids (PFAAs) have been widely used as surfactants and surface protectors, performance chemicals, lubricants and pesticides. However, concerns have been raised due to their environmental persistence, toxicity, long-range transport and bioaccumulation properties (Takagi et al., 2011; Lescord et al., 2015; Liu et al., 2015a). These chemicals have been detected in many components of the environment, and some of PFAAs are believed to be ubiquitously present in both the natural environment and biota (Post et al., 2013; Miralles-Marco and Harrad, 2015). They are transported in surface water and air (Wang et al., 2015) leading to their deposition in oceans, soil and groundwater (Sharma et al., 2015; Zhao et al., 2016; Armitage et al., 2006).

Perfluorooctane sulfonate (PFOS) and perfluorooctanoic acid (PFOA) are two of the most frequently detected PFAAs in the environment (Wang et al., 2015). Due to their adverse environmental impacts and potential health risks, PFOS have been listed in a series of national and multilateral regulation agreements including the Stockholm Convention in 2009 (UNEP, 2009; USEPA, 2009); while 2010/2015 PFOA Stewardship Program was implemented to reduce PFOA emission (USEPA, 2006). Although production and application of PFOS and PFOA have been discontinued in Europe and America (USEPA, 2009), they have continued to increase in China due to supply on-going domestic and international demands (Wang et al., 2016a). After a decade of continuous expansion, China's annual production capacity of PFOS and PFOA plateaued at approximately 220-240 t/yr by 2011 and 150 t/yr by 2013, respectively (Liu et al., 2008; Li et al., 2015). The widespread contamination and the associated risks to environment and human health remain a concern for the scientific community and government regulators.

PFOS and PFOA can be released to the surrounding environment during manufacturing and use of PFOS/PFOA-containing products (Wang et al., 2014a). Local PFOS contamination is usually associated with discharge from industries such as PFOS manufacturing, metal plating, textile treatment and the semi-conductor industry, while hot spots of PFOA contamination are derived from production and fluoropolymer (FP) manufacturing and processing (Lim et al., 2011; Prevedouros et al., 2006; Wang et al., 2016b). The occurrence of PFOS/PFOA pollution hotspots in soil, water and air associated with manufacturing facilities have been increasingly reported in China (Chen et al., 2009; Wang et al., 2015). However, the broader picture of pollution pathways for PFOS/PFOA into different environmental compartments and their quantification across China have not been established. The purpose of this study was to provide a comprehensive estimation of PFOS and PFOA release into the Chinese environment.

\section{Identification of sources and pollution pathways}

There are two major sources for PFOS/PFOA pollution in China, that from the domestic source and that from the industrial source (a major component in China) (Fig. 1). The initial recipients for this release are soil and surface water. Industrial emission of PFOS/PFOA mainly includes two pollution pathways: (i) PFOS/PFOA discharged into surface waters via industrial wastewater (Wang et al., 2012, 2014c and (ii) PFOS/PFOA emission to air followed by deposition to surface water and terrestrial surfaces. Given their mobile characteristics, those deposited into the terrestrial environment will ultimately run off into surface water or infiltrate deeper into soil (Xiao et al., 2012a; Shan et al., 2015). The PFOS/PFOA in domestic products can be released into surface water through municipal wastewater treatment plants (MWWTPs) (Zhang et al., 2013). In certain cases, the concentrations of PFAAs especially for PFOA, increase from the influent to the effluent of MWWTPs, suggesting the partial biodegradation of precursors during the biological treatment (Xiao et al., 2012b). Those that do not escape directly may be trapped in biosolids in the MWWTPs or enter landfill with the disposal of unwanted products. In both cases further leaching into soils and surface/ groundwater are possible. Other sources include the dispersion of aqueous fire-fighting foam (AFFF), and the natural breakdown of the pesticides in agriculture including sulfluramid both of which can be released into soil (Chen et al., 2012; Zhang et al., 2013; Löfstedt Gilljam et al., 2015; Yan et al., 2015). Both PFOS and PFOA can enter into groundwater mainly through surface water seepage and soil leaching (Xiao et al., 2015; Liu et al., 2016).

\section{Estimation methods of environmental releases}

The production process commonly used by Chinese PFOS and PFOA manufacturers is electrochemical fluorination (ECF), which was previously used by global producers. The ratio of linear to branched perfluorinated C chains is roughly $70 \%$ to $80 \%$ linear and $20 \%$ to $30 \%$ branched in the case of the synthesis of PFOS and PFOA (Buck et al., 2011). Considering a large part of PFOS/PFOA produced in China meets the domestic demands, the release estimation took into account both the linear and branched isomers of PFOS/PFOA as possible. After a decade of substantial increase in production and use of PFOS and PFOA in China this has plateaued over the period of 2010 to 2013 (Wang et al., 2015; Li et al., 2015). The vast majority of PFOS and PFOA were emitted in the central and eastern region of China, where the developed industrial and commercial areas are centred. The first step in the study was to collect and examine emission data for PFOS and PFOA from the central and eastern region of China in 2010-2013. Industrial emission data of PFOS are derived from major sources including PFOS manufacturing, metal plating, textile treatment and semi-conductor industry, while those for PFOA come from PFOA production, FP manufacturing and processing, use of aqueous fluoropolymer dispersions (AFDs) and industrial processes of perfluorooctane sulfonyl fluoride (POSF)- and fluorotelomer (FT)-based products. Domestic emission data of PFOS/PFOA were mainly collected on domestic wastewater, landfill leachate and application of AFFF, pesticide, and biosolids. The next step was to estimate transport processes such as atmospheric deposition, runoff, soil leaching and surface water seepage. The presence of PFOS/PFOA in different environmental compartments, following the release from different routes was then calculated.

When collecting and further processing the emission data for PFOS and PFOA, PFOS precursors included perfluorooctane sulfonamides (FOSAs) and perfluorooctane sulfonamidoethanols (FOSEs), while PFOA precursors primarily refered to fluorotelomer alcohols (FTOHs), FOSAs and FOSEs (Buck et al., 2011). Some precursors such as FTOHs, FOSAs and FOSEs are industrial products, and may be released to the environment during the process of manufacturing and use. Both FOSAs and FOSEs are produced from POSF, while FTOHs is manufactured from FT (Prevedouros et al., 2006). In addition, these precursors were 


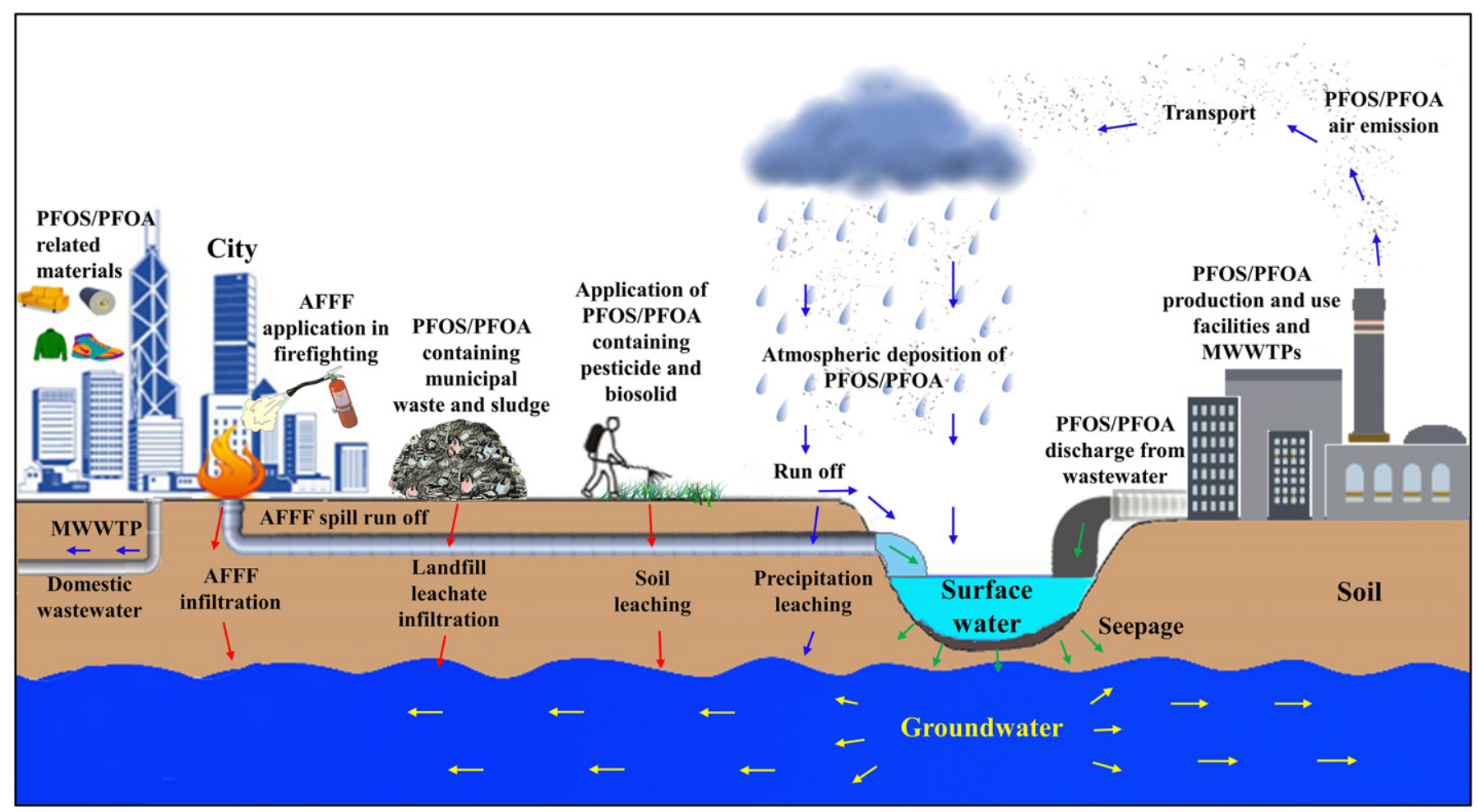

Fig. 1. Schematic diagram of sources and pollution pathways for PFOS/PFOA.

also released as impurities or by-products when manufacturing other FT-based or POSF-based products including PFOS and PFOA (Lim et al., 2011; Wang et al., 2014a). Environmental release data for these precursors were collected or calculated based on their production/use and corresponding emission factors as well as their presence as impurities in different industrial processes and products (Xie et al., 2013a; Li et al., 2015). These precursors were assumed to be ultimately converted to PFOS/PFOA equivalents.

\subsection{Contamination of surface water and soil}

\subsubsection{Wastewater and sewage sludge discharge}

For industrial wastewater, the release estimation of PFOS/PFOA was based on the quantity of PFOS/PFOA-related chemicals produced or used and the emission factors to water for a relevant industry. Using this approach, the release of PFOS and PFOA through industrial wastewater discharge was estimated to be $58 \mathrm{t} / \mathrm{yr}$ and $27.3 \mathrm{t} / \mathrm{yr}$, respectively (Xie et al., 2013a; Li et al., 2015). The starting point for an estimation of PFOS/PFOA release through domestic wastewater discharge was the assumption that PFOS, PFOA and precursors would enter the drain/ sewer system and further MWWTPs following cleaning, wiping and washing of the products in the domestic environment. Regional emissions of PFOS/PFOA from local MWWTPs can be estimated from corresponding statistical data on population density (PD) and per capita disposable income (PCDI) (Xie et al., 2013b; Li et al., 2015). Based on the estimation equations and regional statistical data, release of PFOS/ PFOA via MWWTP emission ( $\mathrm{E}_{\mathrm{MWwTP}}$ ) was calculated in this study (detailed description and data in Supplementary material and Table S1). Total discharge amount of FOSA and N-ethyl perfluorooctane sulfonamidoacetic acid (EtFOSAA), which passed through the MWWTPs without degradation, were $\sim 5 \%$ of those for PFOS and $\sim 2 \%$ of those for PFOA on average, based on monitoring data from 28 MWWTPs in 11 cities of central and eastern China (Zhang et al., 2013). The predicted releases of these precursors from MWWTPs were then further converted to PFOS and PFOA equivalents through respective transformation factors (detailed description in Supplementary Material). The mass flow of PFOS/PFOA in wastewater and sewage sludge from 43 MWWTPs in these regions was also collected to calculate emission proportion through domestic wastewater ( $\mathrm{P}_{\text {MwwTP water }}$ ) and through sewage sludge $\left(\mathrm{P}_{\text {MwwTP sludge }}\right)$ (reviewed in Table S2). Eq. (1) was used to estimate the release of PFOS/PFOA $\left(\mathrm{W}_{\mathrm{MWwTP}}\right)$ in domestic wastewater to surface water.

$\mathrm{W}_{\mathrm{MWWTP}}=\mathrm{E}_{\mathrm{MWWTP}} \times \mathrm{P}_{\mathrm{MWWTP}}$ water

In China, approximately 8.5 million ton dry weight of municipal sewage sludge (biosolid) are generated each year (Zhang et al., 2013). It is calculated that the biosolids would contain average concentrations of $18 \mathrm{ng} / \mathrm{g}$ for PFOS and $8.3 \mathrm{ng} / \mathrm{g}$ for PFOA. About $48 \%$ of these biosolids were applied to land via agriculture and urban greening ( $\mathrm{P}_{\text {Biosolid applica- }}$ tion ) as a soil amendment while $35 \%$ of them were disposed as landfill ( $\left.P_{\text {Biosolid landfill }}\right)$ (Chen et al., 2012). No further treatment occurs for these PFOS/PFOA in biosolids in landfill or when applied to the local soil compartment (Lindstrom et al., 2011). Eqs. (2) and (3) were used to estimate the release and leaching of PFOS/PFOA into soil from biosolid application to the land ( $\left.\mathrm{S}_{\text {biosolid application }}\right)$ and landfill ( $\left.\mathrm{S}_{\text {biosolid landfill }}\right)$.

$$
\begin{aligned}
& \mathrm{S}_{\text {biosolid application }}=\mathrm{E}_{\mathrm{MWWTP}} \times \mathrm{P}_{\mathrm{MWWTP} \text { biosolid }} \times \mathrm{P}_{\text {biosolid application }} \\
& \mathrm{S}_{\text {biosolid landfill }}=\mathrm{E}_{\mathrm{MWWTP}} \times \mathrm{P}_{\mathrm{MWWTP} \text { biosolid }} \times \mathrm{P}_{\text {biosolid landfill }}
\end{aligned}
$$

\subsubsection{Aqueous fire-fighting foam (AFFF) runoff and infiltration}

Perfluorooctane sulfonyl fluoride (POSF)-based AFFF, is mainly produced by consuming the PFOS-salts, and is the predominant type of fire fighting foam in China, a product also known to contain PFOA impurities (Lim et al., 2011; Andreas and Leo, 2009). During the application of AFF, PFOS is directly released to the environment as a major ingredient, while PFOA is released as an impurity. Unfortunately, since there is a lack of information on PFOS/PFOA precursor contents, these substances were not taken into account in the calculation. The concentration ratio of PFOS:PFOA in POSF-based AFFF, produced by a similar process to 
those in China, has been estimated to be 10:1 or even lower (Andreas and Leo, 2009). The emission of PFOS in AFFF application to the environment was estimated to be $7 \mathrm{t} / \mathrm{yr}$ (Xie et al., 2013a). According to the PFOS:PFOA ratio (10:1) in POSF-based AFFF, a more modest emission of PFOA was estimated at $0.7 \mathrm{t} / \mathrm{yr}$. When estimating the environmental release of PFOS/PFOA in AFFF, fire training and fire intervention are both considered in the present study (Zhang et al., 2012). The environmental release of PFOS/PFOA during AFFF application was estimated based on a commonly used scenario (Brooke et al., 2004), in which there is no containment of this fire-fighting foam after discharge, which is the case in China, so that $50 \%$ of the release goes to surface water without treatment and 50\% to soil which could ultimately leach to groundwater. Therefore, the release of PFOS in AFFF application to both surface water and soil were considered to be $3.5 \mathrm{t} / \mathrm{yr}$ respectively, while those of PFOA were $0.35 \mathrm{t} / \mathrm{yr}$ respectively.

\subsubsection{Atmospheric deposition, runoff and infiltration}

The air emission of PFOS from production and metal plating was estimated to be $1.3 \mathrm{t} / \mathrm{yr}$. For PFOA emissions to the atmosphere these were estimated at $7.3 \mathrm{t} / \mathrm{yr}$ according to previous calculations of total environmental emission (40 t) (Xie et al., 2013a; Li et al., 2015). Except for a small amount of PFOS/PFOA precursors, most airborne PFOS/PFOA were believed to combine with particulates, which were deposited to land and ocean (Harada et al., 2006; Barton et al., 2006; Young et al., 2007). In the Bohai Rim, located in the eastern coastal region of China, Liu et al. (2015b) estimated that 65\% of PFOS generated from air emission can be deposited on the local land and the remaining transported over a longer distance. Although a higher proportion of airborne PFOS/ PFOA would be deposited to land in some inland regions, the proportion (65\%) was selected but some caution is required as there is as yet no large amount of research on atmospheric transport available for them. The air emission of PFOS/PFOA was assumed to be evenly deposited to a large surrounding expanse of terrestrial surface and surface water. The maximum mass fractions of airborne PFOA and PFOS have been observed in particulate matter of $<0.3 \mu \mathrm{m}$ and $<10 \mu \mathrm{m}$, respectively, most of which would ultimately be deposited by wet precipitation (Barton et al., 2006; Harada et al., 2006; Liu et al., 2015b). Removal by precipitation was also expected to take out both the smallest size particles $(<1 \mu \mathrm{m})$ and the coarser size particles $(<10 \mu \mathrm{m})$ (Taniyasu et al., 2013; Dreyer et al., 2015). In general, $80 \%-90 \%$ of atmospheric particulate matter were presumed to be captured in wet deposition while dry deposition would only account for 10\%-20\% (Dai, 2006; Shan et al., 2015). In this study, proportions of wet deposition ( $\left.\mathrm{P}_{\text {wet depostion }}\right)$ was conservatively estimated to be $80 \%$ and the remaining $20 \%$ ( $P_{\text {dry depostion }}$ ) were attributed to dry deposition. The proportion of exposed surface water, both rivers and lakes, in the provinces of central and eastern China were calculated to be $5.7 \%$ for average percentage of surface water area ( $\mathrm{P}_{\text {surface water }}$ (IGSNNR, 2014). Eq. (4) can be used to calculate the contamination of surface water by PFOS/PFOA $\left(\mathrm{W}_{\text {deposition }}\right)$ via air emission and subsequent direct deposition, where $\mathrm{E}_{\mathrm{air}}$ represented air emission of PFOS/PFOA and $\mathrm{P}_{\text {land }}$ represented the proportion of airborne PFOS/ PFOA deposited to the land.

$\mathrm{W}_{\text {deposition }}=\mathrm{E}_{\text {air }} \times \mathrm{P}_{\text {land }} \times \mathrm{P}_{\text {surface water }}$

What is the fate of the PFOS/PFOA that is deposited on the terrestrial environment? With the exception of direct deposition to surface water, most PFOS/PFOA arriving through dry deposition would reach soil and vegetation, and those present in vegetation would also reach the soil through litter fall and washout. Both the EU system for the evaluation of substances model and the Berkeley-Trent model estimate that $<0.3 \%$ of PFOS in soil would be entrained in runoff and be transported to surface water, which is a negligible proportion (Brooke et al., 2004; Liu et al., 2015a). Due to broadly similar physicochemical properties (e.g. $\log \mathrm{K}_{\mathrm{oc}}$ ) between PFOS and PFOA, this study assumed that PFOS and PFOA in soil entrained by runoff to surface water could be negligible. Based on annual precipitation and runoff, an average runoff coefficient $\left(C_{\text {runoff }}\right)$ in eastern and central China was calculated to be 0.34 , which was approximate to the median of runoff coefficients (0-0.8) for natural surface (IGSNNR, 2014). The PFOS/PFOA not captured in runoff, would enter deeper within soil through infiltration. Eqs. (5) and (6) can be used to calculate the release of PFOS/PFOA through runoff to surface water $\left(\mathrm{W}_{\text {runoff }}\right)$ and through atmosphere deposition to soil ( $\left.\mathrm{S}_{\text {precipitation}}\right)$.

$$
\begin{aligned}
\mathrm{W}_{\text {runoff }}= & \mathrm{E}_{\text {air }} \times \mathrm{P}_{\text {land }} \times \mathrm{P}_{\text {wet depostion }} \times\left(1-\mathrm{P}_{\text {surface water }}\right) \times \mathrm{C}_{\text {runoff }} \\
\mathrm{S}_{\text {deposition }}= & \mathrm{E}_{\text {air }} \times \mathrm{P}_{\text {land }} \times\left(1-\mathrm{P}_{\text {surface water }}\right) \\
& \times\left[\mathrm{P}_{\text {dry depostion }}+\mathrm{P}_{\text {wet depostion }} \times\left(1-\mathrm{C}_{\text {runoff }}\right)\right]
\end{aligned}
$$

\subsubsection{Landfill leachate infiltration}

In China, most landfills are not adequately lined to prevent leachate migration. The total leakage of PFAAs from landfill leachate ( $\left.\mathrm{E}_{\text {landfill }}\right)$ to local soil and groundwater in China was estimated to be $3.1 \mathrm{t} / \mathrm{yr}$ with approximately $81 \%$ of the national leakage coming from the central and eastern regions (NBS, 2014). Based on the concentrations of individual PFAA found in landfill leachate (Yan et al., 2015), the percentage of PFOS and PFOA in landfill that could enter the leachate $\left(\mathrm{P}_{\text {landfill }}\right)$ were estimated to be $3.3 \%$ and $60 \%$, respectively. Eq. (7) can be used to estimate the amount of PFOS/PFOA released from landfill to soil $\left(S_{\text {landfill }}\right)$. As landfill in China mainly consists of biosolids and municipal solid waste (MSW), PFOS/PFOA ( $\mathrm{S}_{\mathrm{MSW}}$ ) derived from MSW can be estimated by total release in landfill leachate $\left(S_{\text {landfill }}\right)$ and those derived from biosolid landfill ( $S_{\text {biosolid landfill }}$ ) (Eq. (8)).

$\mathrm{S}_{\text {landfill }}=\mathrm{E}_{\text {landfill }} \times \mathrm{P}_{\text {landfill,central and eastern China }} \times \mathrm{P}_{\text {landfill }}$

$\mathrm{S}_{\mathrm{MSW}}=\mathrm{S}_{\text {landfill }}-\mathrm{S}_{\text {biosolid landfill }}$

\subsubsection{Pesticide infiltration}

In China, sulfluramid is the predominant PFOS/PFOA-related pesticide, which was used to estimate PFOS/PFOA release from pesticide in this study (Zhang et al., 2012). The main active ingredient in sulfluramid is N-ethyl perfluorooctane sulphonamide (Et-FOSA) (Löfstedt Gilljam et al., 2015), which would ultimately transform to PFOS and PFOA through photolysis, oxidation, and biotransformation (Tomy et al., 2004; Martin et al., 2006; Plumlee et al., 2009). Furthermore, PFOS and PFOA were also released to the environment as impurities in sulfluramid. For sulfluramid containing pesticides, the vast majority are released into the terrestrial environment during application. The environmental release of PFOS has been estimated to be $2.6 \mathrm{t}$ /a by Zhang et al. (2012), while the release of PFOA from this source was calculated to be $1.4 \mathrm{t} / \mathrm{a}$ based on the annual consumption of Et-FOSA for sulfluramid, and the transformation rate to PFOA and PFOA content as impurities in sulfluramid (detailed description in Supplementary Material). The amount of sulfluramid in applied in the central and eastern region of China accounted for $96 \%$ of the total national use $\left(\mathrm{P}_{\text {pesticide, central and eastern }}\right.$ China) (Zhang et al., 2012). According to emission factors for pesticides used in personal/domestic situations from the Technical Guidance Documents (TGDs) (European Commission, 2003), 90\% of sulfluramid $\left(\mathrm{P}_{\text {soil }}\right)$ would release to local soil during use. The release of PFOS/PFOA ( $S_{\text {pesticide }}$ ) from pesticide application to soil can be estimated by Eq. (9).

$\mathrm{S}_{\text {pesticide }}=\mathrm{E}_{\text {pesticide }} \times \mathrm{P}_{\text {pesticide,central and eastern China }} \times \mathrm{P}_{\text {soil }}$ 


\subsection{Groundwater contamination}

\subsubsection{Surface water seepage}

Contaminated surface water seepage is a major pollution pathway for PFOS/PFOA in groundwater (Lin et al., 2015; Liu et al., 2016). Official data concerning total groundwater recharge $\left(V_{\text {total recharge }}\right)$, recharge from surface water $\left(P_{\text {surface water recharge }}\right)$ and total surface water volume ( $\left.V_{\text {surface water }}\right)$ in central and eastern region of China were used to calculate seepage rates of PFOS/PFOA from surface waters ( $\mathrm{SR}_{\text {surface water }}$ ) (Table S4) (MWR, 2011, 2013) [Eq. (10)]. Using a multimedia fate model for PFOS in the Bohai Rim of China, the proportion adsorbed by sediment was calculated to be about $5 \%$ of the total release in surface water $\left(\mathrm{P}_{\text {sediment absorption }}\right)$ (Liu et al., 2015a). Due to a similar $\log \mathrm{K}_{\mathrm{oc}}$ between PFOS (2.4-4.7) and PFOA (1.3-4.5), this proportion was used to estimate the amount adsorbed by sediment (Higgins and Luthy, 2006; Johnson et al., 2007; Ferrey et al., 2009; Ahrens et al., 2011; Li et al., 2012). Eq. (11) was used to estimate the release of PFOS/PFOA through surface water seepage to groundwater $\left(\mathrm{G}_{\text {seepage }}\right)$.

$\mathrm{SR}_{\text {surface water }}=\frac{\mathrm{V}_{\text {total recharge }} \times \mathrm{P}_{\text {surface water recharge }}}{\mathrm{V}_{\text {surface water }}}$

$\mathrm{G}_{\text {seepage }}=\mathrm{E}_{\text {surface water }} \times\left(1-\mathrm{P}_{\text {sediment absorption }}\right) \times \mathrm{SR}_{\text {surface water }}$

\subsubsection{Soil leaching into groundwater}

Due to their relatively high solubility in water and $\operatorname{low} \log \mathrm{K}_{\mathrm{oc}}\left(\log \mathrm{K}_{\mathrm{oc}}\right.$ of 3.0 and 2.8), the potential for PFOS/PFOA in soil ( $\left.E_{\text {soil }}\right)$ to be leached into groundwater by precipitation or irrigation is found to be high (Zareitalabad et al., 2013; Xiao et al., 2015). In the present study, the high leaching potential was mainly attributed to the relatively high irrigation intensity and precipitation in central and eastern China (NBS, 2014). The leaching percentage of PFOS/PFOA ( $\left.\mathrm{P}_{\text {leaching }}\right)$ in soil was estimated to be $90 \%$, which was based on results reported from leaching experiments (Gellrich et al., 2012; Zareitalabad et al., 2013). According to a long-term pilot study, only $0.001 \%$ of PFOA and $0.004 \%$ of PFOS in soil could be accumulated by vegetation (winter rye, canola, winter wheat and winter barley), which was negligible in this estimation (Stahl et al., 2013). As the main grain producing areas in China, large areas of the land contain crops requiring irrigation in the central and eastern regions (NBS, 2014). Therefore, Eq. (12) was used to estimate release of PFOS/PFOA through soil leaching into groundwater ( $\left.\mathrm{G}_{\text {soil leaching }}\right)$.

$\mathrm{G}_{\text {soil leaching }}=\mathrm{E}_{\text {soil }} \times \mathrm{P}_{\text {leaching }}$

\section{Results and discussion}

\subsection{Major sources screening and release comparison}

Overall about $70 \mathrm{t} / \mathrm{yr}$ of PFOS and $40 \mathrm{t} / \mathrm{yr}$ of PFOA were estimated to be released into the environment in central and eastern China (Fig. 2). The most important observation here is that this contamination was dominated by industrial emissions which contributed $86 \%$ of PFOS and $87 \%$ of PFOA to this environmental release. This clearly shows the unique challenge faced by China. The vast majority of this industrial emission was in wastewater discharged to surface water. Although not important in terms of quantity of release, it can be observed that the release of PFOS to the air compartment from industrial emission ( $1.3 \mathrm{t} / \mathrm{yr}$ and $1.9 \%$ of the total environmental emission) was significantly lower than for PFOA ( $7.3 \mathrm{t} / \mathrm{yr}$ and $18 \%$ of the total emission). The low PFOS air emission is due to their being only two PFOS-related industrial processes, PFOS production and metal plating (Paul et al., 2008). In contrast, each main PFOA-related industrial process, including PFOA production, FP manufacturing and processing, use of aqueous fluoropolymer dispersions (AFDs) and production of POSF- and FTbased products, contributed air emission of PFOA, and the total release is considerable (Wang et al., 2014a, 2014b).

Overall, domestic emissions are a much less important source of contamination in central and eastern China in terms of quantity (Fig. 2).

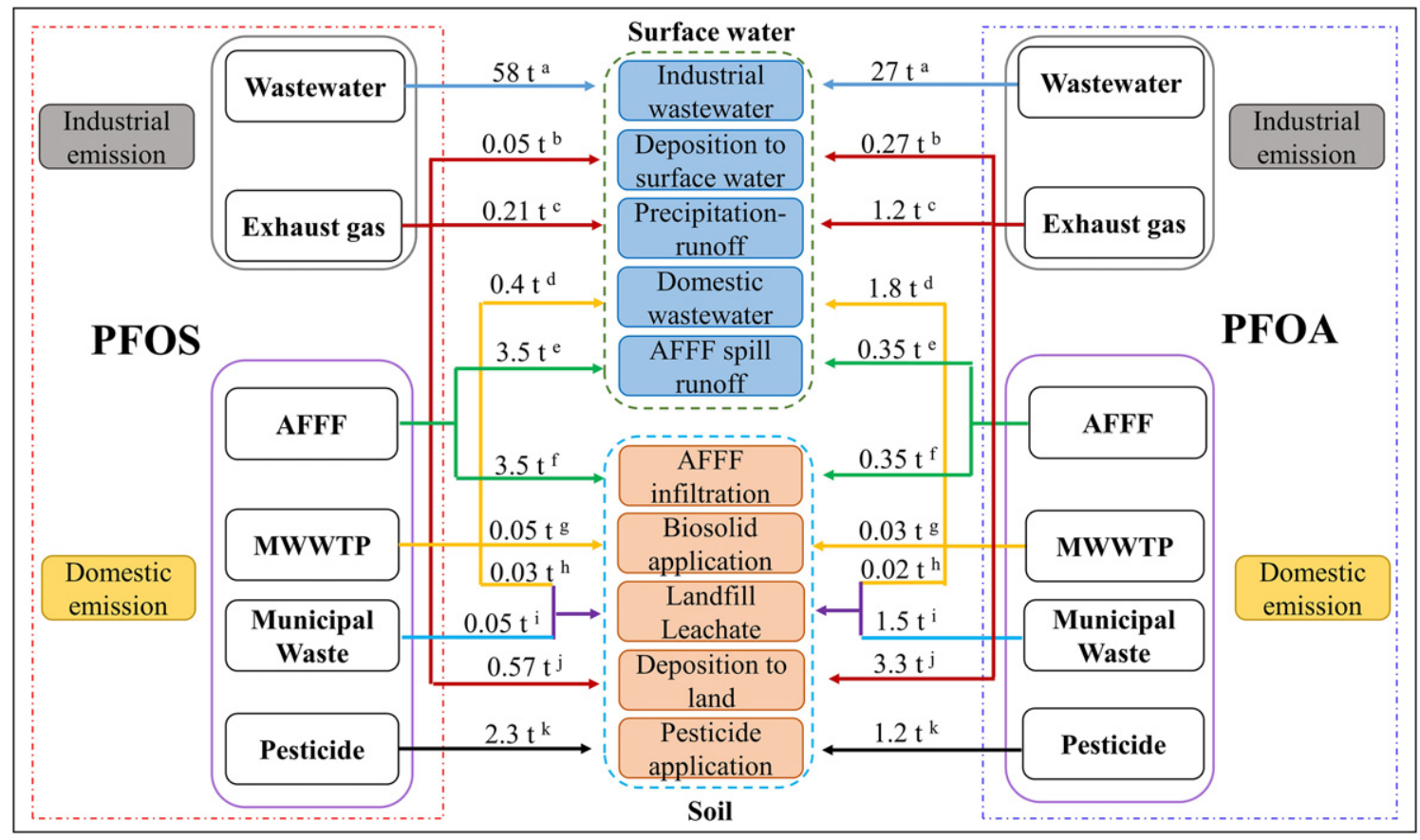

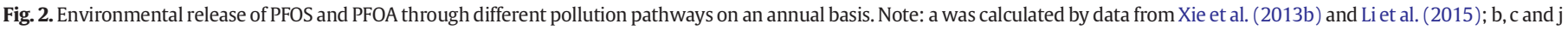

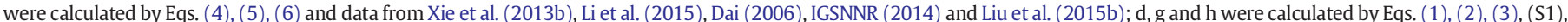

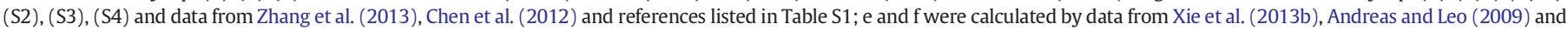

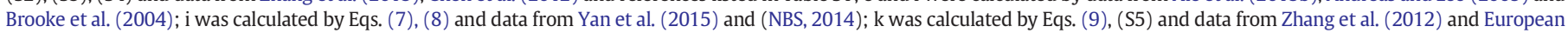
Commission (2003) 
The higher emissions of PFOS compared to PFOA were linked to its use in AFFF and in pesticides. The release of PFOA in domestic wastewater was about 4 times of those of PFOS. However, the emission proportion of PFOA (3.2\%) derived from sewage sludge (biosolid) was much lower than those for PFOS (21\%). This is linked to the slightly higher $\log \mathrm{K}_{\mathrm{oc}}$ of PFOS compared to PFOA (Higgins and Luthy, 2006). Release of PFOA in landfill leachate derived from municipal solid waste (mainly consisting of domestic garbage) was two orders of magnitude higher than that of PFOS. The higher PFOA releases from domestic wastewater and garbage were considered to be linked to its higher relative use in the home following the gradual phase-out of PFOS-based chemicals by the Chinese government (Wang et al., 2009).

\subsection{Contribution estimation of PFOS and PFOA in different pathways}

In China, from all sources about $62 \mathrm{t} / \mathrm{yr}$ of PFOS were estimated to be released into surface water. Industrial wastewater was the dominant pollution pathway of PFOS in surface water and contributed about 93\% (Fig. 3). Due to the relatively high content of PFOS ( $0.4-0.6 \%$ by weight) in AFFF, this was the second most important source. The release of PFOS to soil was estimated at $7 \mathrm{t} / \mathrm{yr}$ in central and eastern China. The majority of soil contamination came from the use of AFFF and pesticide. Total contribution from other pollution pathways was $<11 \%$.

Like PFOS, the major release to surface water from PFOA came from industry (Fig. 3). However, a larger proportion of PFOA emission came

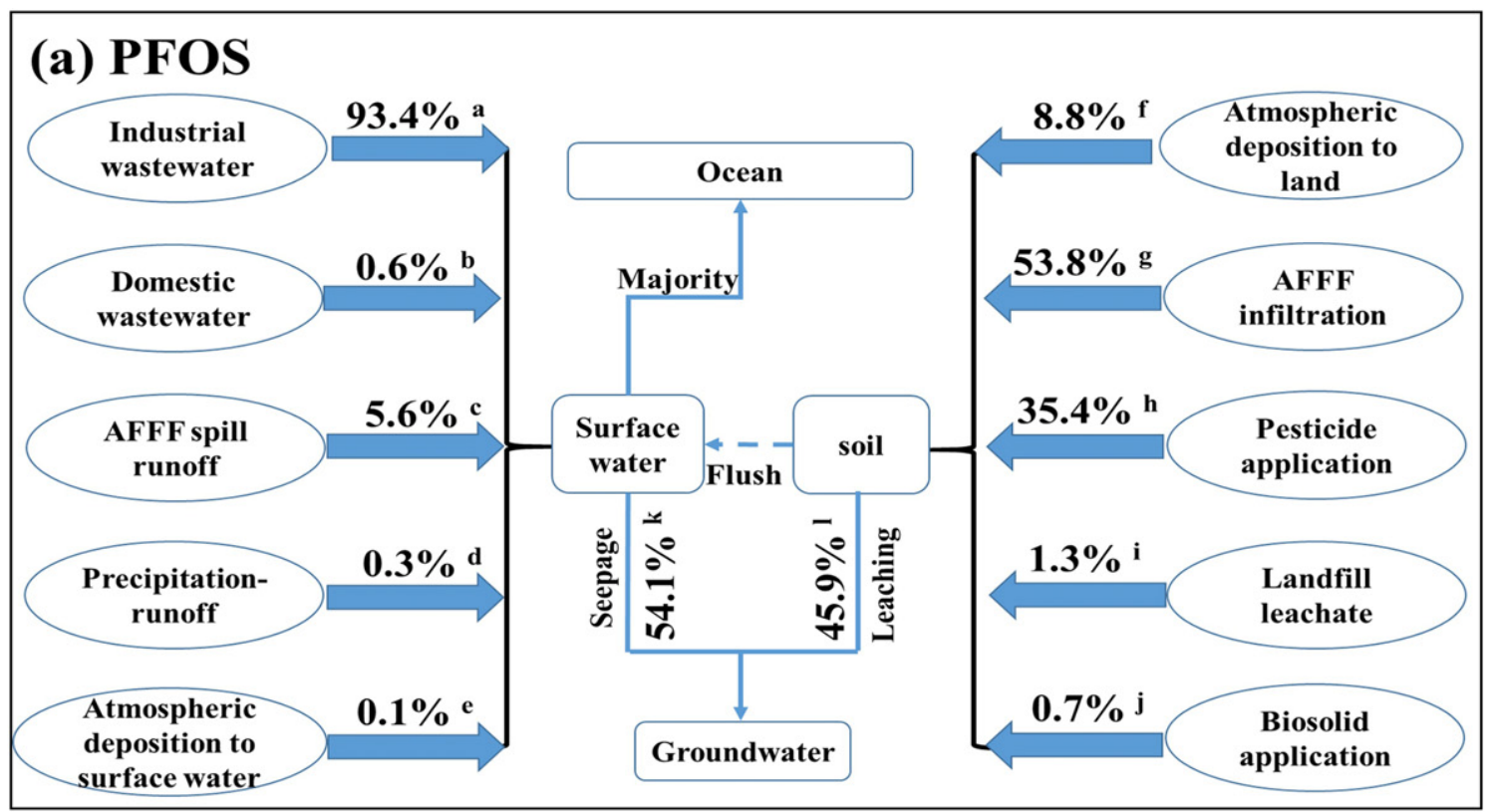

\section{(b) PFOA}

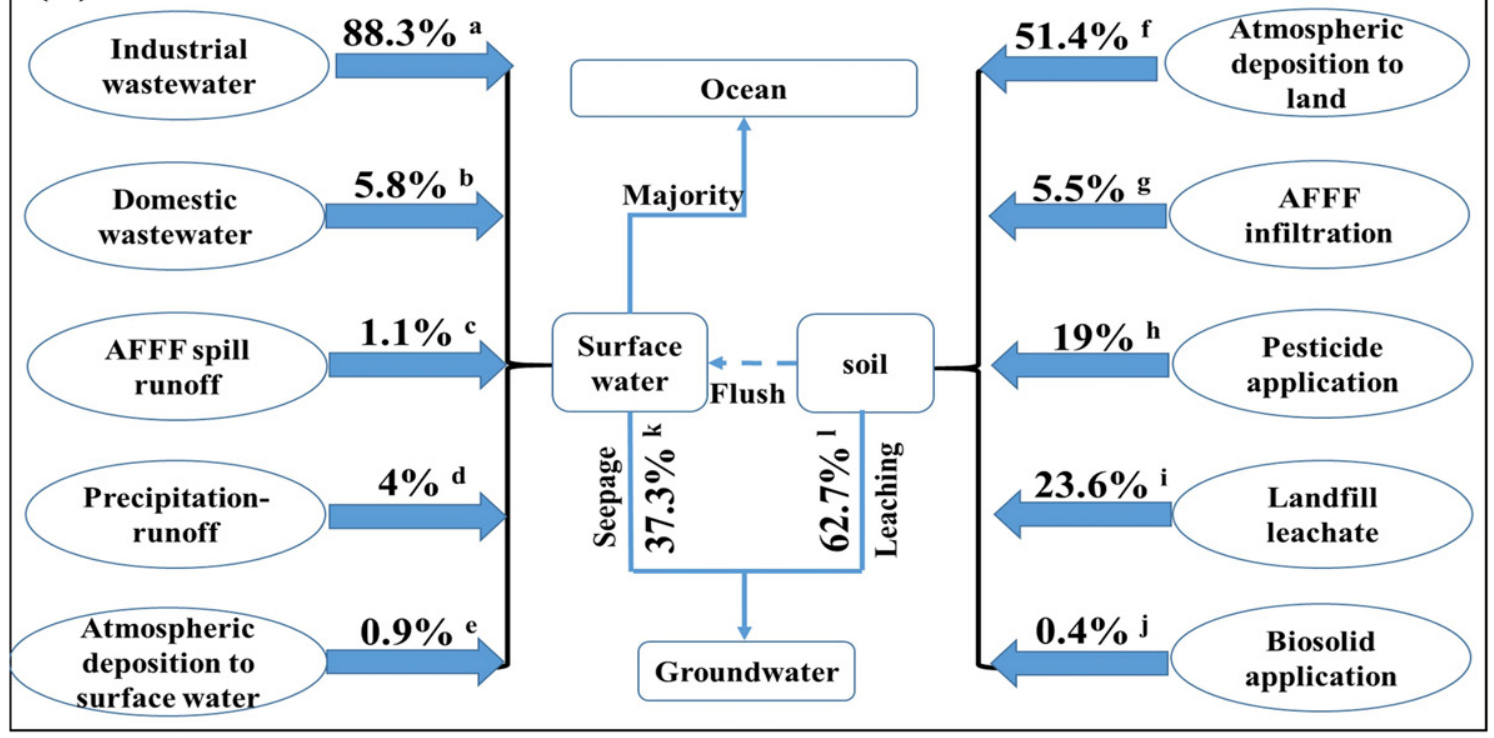

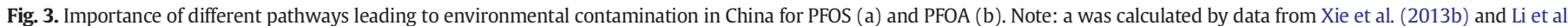

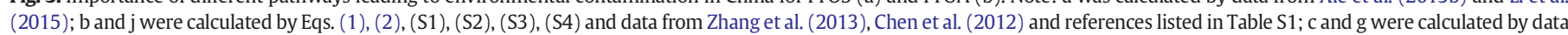

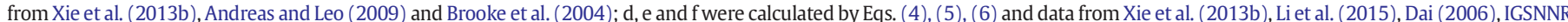

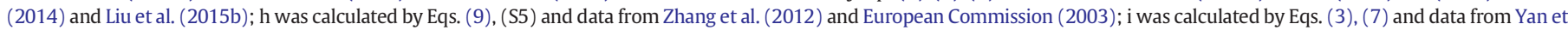

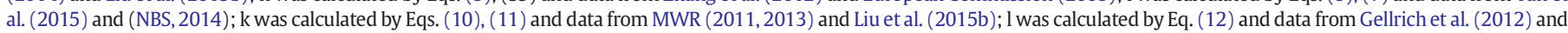
Zareitalabad et al. (2013). 
from MWWTP discharge (5.8\%) and precipitation-runoff (4\%). About $6 \mathrm{t} / \mathrm{yr}$ of PFOA was released into soil and much of this was attributed to atmospheric deposition. Landfill leachate and pesticide application were next in proportion as sources of soil contamination.

Because of their persistence and mobility, groundwater and ocean were the predominant ultimate sinks of PFOS/PFOA. The majority of PFOS/PFOA in surface water will eventually flow into the ocean (Liu et al., 2015a). Surface water seepage and soil leaching contributed almost all of the PFOS/PFOA in groundwater. Due to absorption and retardation by soil particles, the leaching of PFOS/PFOA would occur over a relatively long and slow process of several years depending on groundwater depth (Xiao et al., 2015). Therefore, transport of PFOS/PFOA through surface water seepage was transient and fast, while the movement of PFOS/ PFOA through soil leaching was expected to be long lasting and slow.

\subsection{Uncertainty analysis and study limitation}

In this study, release estimations of PFOS/PFOA via industrial wastewater and exhaust gas may be conservative compared to the actual values. This is because industrial emission data of PFOS/PFOA were calculated based on emission factors and impurity content for developed countries, where stricter emission regulations have been enforced. Due to a shortage of sufficient detailed emission data in China, only major sources of PFOS/PFOA were considered for release estimations. Since some sources such as paper making, oil exploitation and traffic, in which PFOS/PFOA-related chemicals are used in very small quantities, were not considered an underestimation is expected of PFOS/
PFOA release to different environment media. In addition, except for the main pollution pathways discussed in the study, plant bioaccumulation, runoff scouring, and diffusion between environmental media are also potential pollution pathways in the environment, although the contribution of PFOS/PFOA through these pathways are very small.

To the best of our knowledge, degradation rates on the precursors are not yet available, or the extent to which PFOS/PFOA may be produced, so the estimated release in this study could tend to reflect the worst case in which all precursors would transform to PFOS/PFOA instantly. In reality, the transformation process of some precursors may be very slow, which may lead to an overestimation of PFOS/PFOA generated by precursors in the different studied media. Although degradation of $\sum$ FOSA was considered in release estimation from MWWTP, there is a shortage of information on the other precursors such as FTOHs acting as sources for PFOS/PFOA in MWWTP emission. There remains a lack of data on the discharge of PFOS/PFOA precursors in landfill leachate and AFFF, which may be another underestimation of PFOS/PFOA release to the environment.

Detailed information on PFOS/PFOA emissions at sub-regional levels is not available. Thus, the study had to take a very broad overview of losses and contamination which may under-represent some sub-regional hot-spots. For example, the proportion of PFOS/PFOA air emission from coastal regions deposited to the land was lower than those from the inland regions. Therefore, there could have been a release underestimation (0-35\%) of PFOS/PFOA through pollution pathways associated with air emission. However, the release underestimation does not significantly change the contribution structure of PFOS/PFOA from these
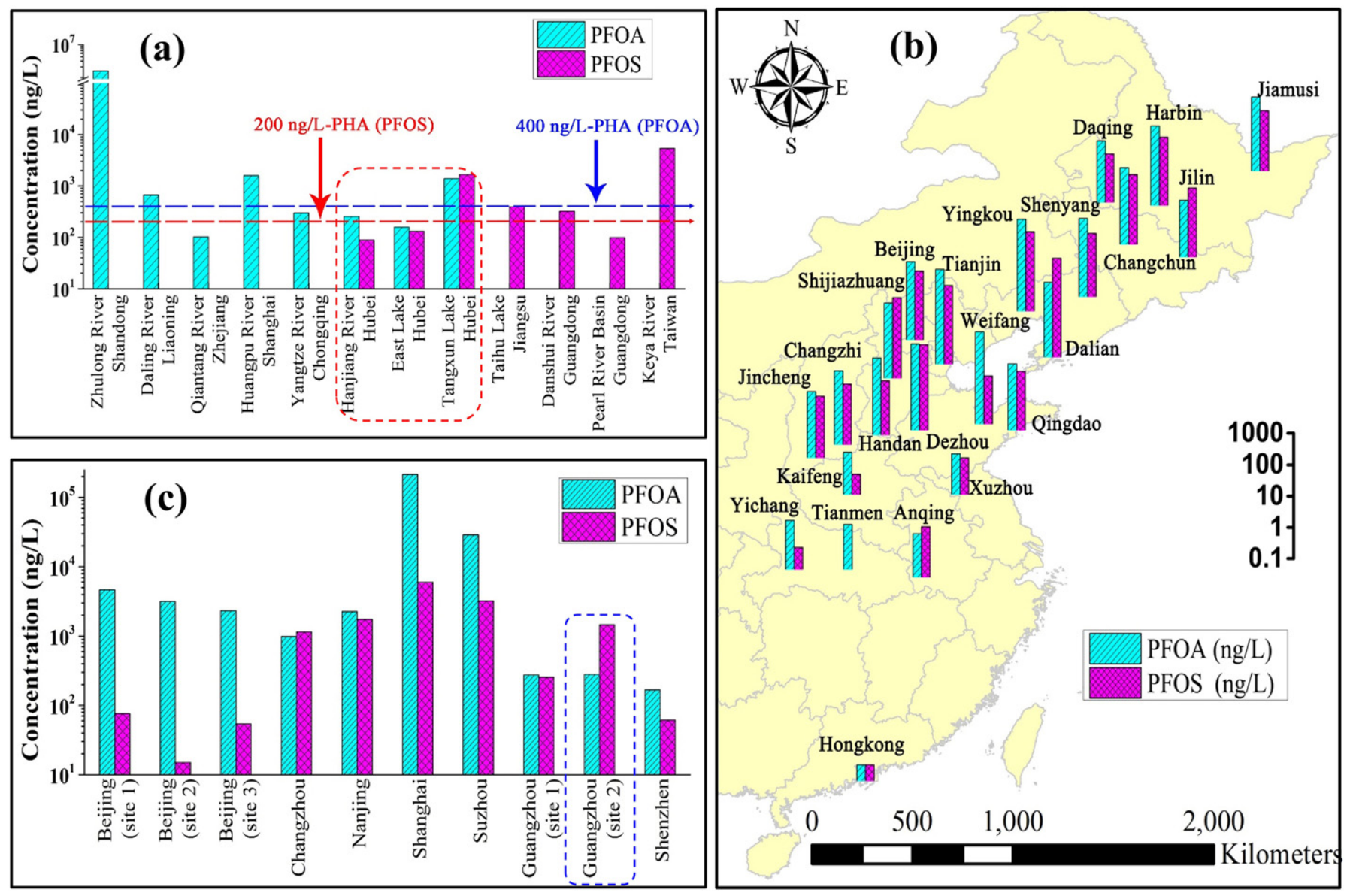

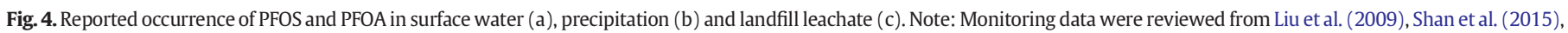
Yi et al. (2012), Yan et al. (2015), Zhang et al. (2014), Wu et al. (2012) and other references listed in Table S5. 
pathways in soil and surface water, for the total air emission of PFOS was relatively small while that of PFOA was very large. Despite these uncertainties, this study should provide a reasonable basis to estimate contribution of air emission to PFOS/PFOA in soil and surface water.

\subsection{Confirmation of field monitoring data for the release estimations}

It has been demonstrated that the emissions from industry are the most important for pollution in China (Figs. 2 and 3). Indeed evidence already exists for industrial wastewater discharge leading to hotspots of PFOS/PFOA in the most developed regions of China (Fig. 4a). Some of these polluted sites have levels comparable to or even much higher than health risk assessment thresholds for drinking water, such as the provisional health advisory (PHA) set by the USEPA (2014) (Fig. 4a). After receiving effluent from PFOS/PFOA-related facilities, the concentrations of PFOA in adjacent river and groundwater were up to $1.7 \mathrm{mg} / \mathrm{L}$ and $240 \mu \mathrm{g} / \mathrm{L}$ in Zibo City (Liu et al., 2016); while PFOS levels were $5.4 \mu \mathrm{g} / \mathrm{L}$ and $61 \mathrm{ng} / \mathrm{L}$ respectively in nearby surface water and groundwater in Taiwan (Lin et al., 2009). Wastewater discharge from numerous PFOS and PFOA related facilities led to high concentrations of these two substances in the surface water in Hubei Province (Wang et al., 2013; Zhou et al., 2013).

Compared with industrial wastewater release, PFOS and PFOA levels caused by domestic wastewater discharge were, as expected, generally low. According to data from 43 MWWTPs in central and eastern China, the average concentrations of PFOS and PFOA in MWWTP effluent were $9.7 \mathrm{ng} / \mathrm{L}$ and $33 \mathrm{ng} / \mathrm{L}$, respectively (reviewed in Table S3). PFOS/PFOA slightly increases in concentration through the MWWTP activated sludge system, probably due to precursor degradation (Dinglasan et al., 2004; Rhoads et al., 2008). In general, the baseline concentrations of PFOS/PFOA in major rivers and lakes were far below assessment threshold of aquatic ecological risk (Fig. S1) (Giesy et al., 2010).

Monitoring data of PFOS/PFOA in wet deposition support the release estimations that were made for the air compartment (Fig. 4b). In particular, in most monitoring sites, PFOA in precipitation showed higher concentrations than PFOS. Due to the limited transport of particle-borne PFOS/PFOA, some high concentrations of PFOS/PFOA in precipitation occurred near industrial sources. The highest concentrations of PFOS and PFOA in precipitation were up to $545 \mathrm{ng} / \mathrm{L}$ and $107 \mathrm{ng} / \mathrm{L}$, respectively (Liu et al., 2009; Shan et al., 2015).

AFFF application and landfill leachate were also prone to cause local risk hotspots. In fire accidents or drills, instantaneous release of hundreds or even thousands liters of AFFF caused $511 \mathrm{ng} / \mathrm{g}$ of PFOS and $418 \mathrm{ng} / \mathrm{g}$ of PFOA in local soil (Yi et al., 2012). In China, a landfill was reported to lose average $7.6 \times 10^{4} \mathrm{~m}^{3} / \mathrm{yr}$ of leachate containing high concentrations of PFOS $(1.2-6 \mu \mathrm{g} / \mathrm{L})$ and PFOA $(0.3-214 \mu \mathrm{g} / \mathrm{L})$ to local soil and groundwater (Fig. 4c) (Zhang et al., 2014; Yan et al., 2015). Some sites of soil and landfill leachate in Guangzhou showed higher concentrations of PFOS than PFOA, which may be due to waste from the local semiconductor industry (Wu et al., 2012). Except for these hotspots, the concentrations of PFOS/PFOA in soil in most areas were at relatively low levels, far below a residential soil screening level by the USEPA (2014) (Fig. S2).

\section{Conclusion and observations}

Overall, the results of this study indicated that:

- About $80-90 \%$ of PFOS/PFOA contamination in the Chinese environment was estimated to come from manufacturing and use facilities mostly via industrial wastewater discharge.

- For PFOS the next most important contamination sources were the use of AFFF and pesticides, while domestic wastewater and industrial exhaust gas losses were much less important.

- For PFOA the most important losses after industrial wastewater were deemed to be from domestic wastewater, industrial exhaust gas and landfill.
- Industrial wastewater, landfill leachate and AFFF application often cause local risk hotspots of PFOS/PFOA in the Chinese environment.

- The most beneficial way to reduce environmental contamination by PFOS/PFOA in China would be to focus on controlling release from industrial wastewater. Local pollution hotspots caused by AFFF application and landfill leachate should also receive attention.

\section{Acknowledgements}

This study was supported by the National Natural Science Foundation of China [Grant Nos. 414201040045 and 41371488]; the International Scientific Cooperation Program [Grant No. 2012DFA91150]; and the Key Project of the Chinese Academy of Sciences [Grant No. KZZDEW-TZ-12]. The UK authors are grateful for support from the NERC Newton fund to assist their collaboration with China.

\section{Appendix A. Supplementary data}

Supplementary data to this article can be found online at http://dx. doi.org/10.1016/j.scitotenv.2016.12.085.

\section{References}

Andreas, B., Leo, M., 2009. Substance flow analysis for Switzerland (EB/OL). http://www. bafuadminch/publ (accessed 14.08.16).

Ahrens, L., Yeung, L.W., Taniyasu, S., Lam, P.K., Yamashita, N., 2011. Partitioning of perfluorooctanoate (PFOA), perfluorooctane sulfonate (PFOS) and perfluorooctane sulfonamide (PFOSA) between water and sediment. Chemosphere 85 (5), 731-737.

Armitage, J., Cousins, I.T., Buck, R.C., Prevedouros, K., Russell, M.H., MacLeod, M., Korzeniowski, S.H., 2006. Modeling global-scale fate and transport of perfluorooctanoate emitted from direct sources. Environ. Sci. Technol. 40 (22), 6969-6975.

Barton, C.A., Butler, L.E., Zarzecki, C.J., Flaherty, J., Kaiser, M., 2006. Characterizing perfluorooctanoate in ambient air near the fence line of a manufacturing facility: comparing modeled and monitored values. J. Air Waste Manage. Assoc. 56 (1), 48-55.

Brooke, D., Footitt, A., Nwaogu, T., 2004. Environmental Risk Evaluation Report: Perfluorooctanesulphonate (PFOS). Environment Agency, Wallingford.

Buck, R.C., Franklin, J., Berger, U., Conder, J.M., Cousins, I.T., de Voogt, P., Jensen, A.A. Kannan, K., Mabury, S.A., van Leeuwen, S.P., 2011. Perfluoroalkyl and polyfluoroalkyl substances in the environment: terminology, classification, and origins. Integr. Environ. Assess. Manag. 7 (4), 513-541.

Chen, C., Lu, Y., Zhang, X., Geng, J., Wang, T., Shi, Y., Hu, W., Li, J., 2009. A review of spatial and temporal assessment of PFOS and PFOA contamination in China. Chem. Ecol. 25 (3), 163-177.

Chen, H., Yan, S., Ye, Z., Meng, H., Zhu, Y., 2012. Utilization of urban sewage sludge: Chinese perspectives. Environ. Sci. Pollut. Res. 19 (5), 1454-1463.

Dai, J., 2006. Environmental Chemistry (in Chinese). Higher Education Press, Beijing.

Dinglasan, M.J.A., Ye, Y., Edwards, E.A., Mabury, S.A., 2004. Fluorotelomer alcohol biodegradation yields poly-and perfluorinated acids. Environ. Sci. Technol. 38 (10), 2857-2864.

Dreyer, A., Kirchgeorg, T., Weinberg, I., Matthias, V., 2015. Particle-size distribution of airborne poly-and perfluorinated alkyl substances. Chemosphere 129, 142-149.

European Commission, 2003. Technical Guidance Document in support of Commission Directive 93/67/EEC on Risk Assessment for New Notified Substances. Commission Regulation (EC) No. 1488/94 on Risk Assessment for Existing Substances and Directive 98/8/EC of the European Parliament and of the Council Concerning the Placing of Biocidal Products on the19 MarketJoint Research Centre, European Chemicals Bureau, Brussels, Belgium.

Ferrey, M., Adair, C., Wilson, J., 2009. Sorption of PFOA and PFOS to aquifer sediment Reprod. Toxicol. 27 (3), 416.

Gellrich, V., Stahl, T., Knepper, T., 2012. Behavior of perfluorinated compounds in soils during leaching experiments. Chemosphere 87 (9), 1052-1056.

Giesy, J.P., Kannan, K., 2001. Global distribution of perfluorooctane sulfonate in wildlife. Environ. Sci. Technol. 35 (7), 1339-1342.

Giesy, J.P., Kannan, K., 2002. Peer reviewed: perfluorochemical surfactants in the environment. Environ. Sci. Technol. 36 (7), 146A-152A.

Giesy, J.P., Naile, J.E., Khim, J.S., Jones, P.D., Newsted, J.L., 2010. Aquatic toxicology of perfluorinated chemicals. Rev. Environ. Contam. Toxicol. 202, 1-52.

Harada, K., Nakanishi, S., Sasaki, K., Furuyama, K., Nakayama, S., Saito, N., Yamakawa, K. Koizumi, A., 2006. Particle size distribution and respiratory deposition estimates of airborne perfluorooctanoate and perfluorooctanesulfonate in Kyoto Area, Japan. Bull. Environ. Contam. Toxicol. 76 (2), 306-310.

Higgins, C.P., Luthy, R.G., 2006. Sorption of perfluorinated surfactants on sediments. Environ. Sci. Technol. 40 (23), 7251-7256.

IGSNRR (Institute of Geographical Sciences and Natural Resources Research, Chinese Academy of Science), 2014o. Thematic database for human-earth system (DB/OL) http://www.dataaccn/jieshaoasp ((in Chinese) (accessed 14.08.16)). 
Johnson, R.L., Anschutz, A.J., Smolen, J.M., Simcik, M.F., Penn, R.L., 2007. The adsorption of perfluorooctane sulfonate onto sand, clay, and iron oxide surfaces. J. Chem. Eng. Data 52 (4), 1165-1170.

Li, C., Ji, R., Schäffer, A., Sequaris, J.-M., Amelung, W., Vereecken, H., Klumpp, E. 2012. Sorption of a branched nonylphenol and perfluorooctanoic acid on Yangtze River sediments and their model components. J. Environ. Monit. 14 (10), 2653-2658.

Lim, T.C., Wang, B., Huang, J., Deng, S., Yu, G., 2011. Emission inventory for PFOS in China: review of past methodologies and suggestions. TheScientificWorldJOURNAL 11, 1963-1980.

Löfstedt Gilljam, J., Leonel, J., Cousins, I.T., Benskin, J.P., 2015. Is ongoing sulfluramid use in South America a significant source of perfluorooctane sulfonate (PFOS)? Production inventories, environmental fate, and local occurrence. Environ. Sci. Technol. 50 (2), 653-659.

Lescord, G.L., Kidd, K.A., De Silva, A.O., Williamson, M., Spencer, C., Wang, X., Muir, D.C 2015. Perfluorinated and polyfluorinated compounds in lake food webs from the Canadian high Arctic. Environ. Sci. Technol. 49 (5), 2694-2702.

Li, L., Zhai, Z., Liu, J., Hu, J., 2015. Estimating industrial and domestic environmental releases of perfluorooctanoic acid and its salts in China from 2004 to 2012 Chemosphere 129, 100-109.

Lin, A.Y.-C., Panchangam, S.C., Lo, C.-C., 2009. The impact of semiconductor, electronics and optoelectronic industries on downstream perfluorinated chemical contamination in Taiwanese rivers. Environ. Pollut. 157 (4), 1365-1372.

Lin, Y.-C., Lai, W.W.-P., Tung, H.-H., Lin, A.Y.-C., 2015. Occurrence of pharmaceuticals, hormones, and perfluorinated compounds in groundwater in Taiwan. Environ. Monit. Assess. 187 (5), 1-19.

Lindstrom, A.B., Strynar, M.J., Delinsky, A.D., Nakayama, S.F., McMillan, L., Libelo, E.L., Neill, M., Thomas, L., 2011. Application of WWTP biosolids and resulting perfluorinated compound contamination of surface and well water in Decatur, Alabama, USA. Environ. Sci. Technol. 45 (19), 8015-8021.

Liu, S., Lu, Y., Xie, S., Wang, T., Jones, K.C., Sweetman, A.J., 2015a. Exploring the fate, transport and risk of perfluorooctane sulfonate (PFOS) in a coastal region of China using a multimedia model. Environ. Int. 85, 15-26.

Liu, B., Zhang, H., Yao, D., Li, J., Xie, L., Wang, X., Wang, Y., Liu, G., Yang, B., 2015b. Perfluorinated compounds (PFCs) in the atmosphere of Shenzhen, China: spatial distribution, sources and health risk assessment. Chemosphere 138, 511-518.

Liu, C., Hu, J., Liu, J., Wan, D., 2008. Pollution status and release of perfluorooctane sulfonate (PFOS) and risk analysis for PFOS in China. Environ. Pollut. 7, 1-9.

Liu, W., Jin, Y., Quan, X., Sasaki, K., Saito, N., Nakayama, S.F., Sato, I., Tsuda, S., 2009. Perfluorosulfonates and perfluorocarboxylates in snow and rain in Dalian, China. Environ. Int. 35 (4), 737-742.

Liu, Z., Lu, Y., Wang, T., Wang, P., Li, Q., Johnson, A.C., Sarvajayakesavalu, S., Sweetman, A.J., 2016. Risk assessment and source identification of perfluoroalkyl acids in surface and ground water: spatial distribution around a mega-fluorochemical industrial park, China. Environ. Int. 91, 69-77.

Martin, J.W., Ellis, D.A., Mabury, S.A., Hurley, M., Wallington, T., 2006. Atmospheric chemistry of perfluoroalkanesulfonamides: kinetic and product studies of the $\mathrm{OH}$ radical and $\mathrm{Cl}$ atom initiated oxidation of $\mathrm{N}$-ethyl perfluorobutanesulfonamide. Environ. Sci. Technol. 40 (3), 864-872.

Miralles-Marco, A., Harrad, S., 2015. Perfluorooctane sulfonate: a review of human exposure, biomonitoring and the environmental forensics utility of its chirality and isomer distribution. Environ. Int. 77, 148-159.

MWR (Ministry of Water Resources, the People's Republic of China), 2011f. Water Resources Bulletin (EB/OL). http://www.mwrgovcn/zwzc/hygb/szygb/qgszygb/201212/ t20121217_335297.html ((in Chinese) (accessed 14.08.16)).

MWR (Ministry of Water Resources, the People's Republic of China), 2013f. Water Resources Bulletin (EB/OL). http://www.mwrgovcn/zwzc/hygb/szygb/qgszygb/ 201411/t20141120_582980.html ((in Chinese) (accessed 14.08.16)).

NBS (National Bureau of Statistics, the People's Republic of China), 2014o. China Statistical Yearbook (M/CD). http://www.statsgovcn/tjsj/ndsj/2014/index.ch.htm ((in Chinese) (accessed 14.08.16)).

Paul, A.G., Jones, K.C., Sweetman, A.J., 2008. A first global production, emission, and environmental inventory for perfluorooctane sulfonate. Environ. Sci. Technol. 43 (2), 386-392.

Plumlee, M.H., McNeill, K., Reinhard, M., 2009. Indirect photolysis of perfluorochemicals: hydroxyl radical-initiated oxidation of $\mathrm{N}$-ethyl perfluorooctane sulfonamido acetate (N-EtFOSAA) and other perfluoroalkanesulfonamides. Environ. Sci. Technol. 43 (10), 3662-3668.

Post, G.B., Louis, J.B., Lippincott, R.L., Procopio, N.A., 2013. Occurrence of perfluorinated compounds in raw water from New Jersey public drinking water systems. Environ. Sci. Technol. 47 (23), 13266-13275

Prevedouros, K., Cousins, I.T., Buck, R.C., Korzeniowski, S.H., 2006. Sources, fate and transport of perfluorocarboxylates. Environ. Sci. Technol. 40 (1), 32-44.

Rhoads, K.R., Janssen, E.M.-L., Luthy, R.G., Criddle, C.S., 2008. Aerobic biotransformation and fate of N-ethyl perfluorooctane sulfonamidoethanol (N-EtFOSE) in activated sludge. Environ. Sci. Technol. 42 (8), 2873-2878.

Stahl, T., Riebe, R.A., Falk, S., Failing, K., Brunn, H., 2013. Long-term lysimeter experiment to investigate the leaching of perfluoroalkyl substances (PFASs) and the carry-ove from soil to plants: results of a pilot study. J. Agric. Food Chem. 61 (8), 1784-1793.

Shan, G., Chen, X., Zhu, L., 2015. Occurrence, fluxes and sources of perfluoroalkyl substances with isomer analysis in the snow of northern China. J. Hazard. Mater. 299, 639-646.

Sharma, B.M., Bharat, G.K., Tayal, S., Larssen, T., Bečanová, J., Karásková, P., Whitehead, P.G., Futter, M.N., Butterfield, D., Nizzetto, L., 2015. Perfluoroalky substances (PFAS) in river and ground/drinking water of the Ganges River basin: Emissions and implications for human exposure. Environ. Pollut. 208, 704-713.
Takagi, S., Adachi, F., Miyano, K., Koizumi, Y., Tanaka, H., Watanabe, I., Tanabe, S., Kannan, K., 2011. Fate of perfluorooctanesulfonate and perfluorooctanoate in drinking water treatment processes. Water Res. 45 (13), 3925-3932

Taniyasu, S., Yamashita, N., Moon, H.B., Kwok, K.Y., Lam, P.K., Horii, Y., Petrick, G., Kannan, K., 2013. Does wet precipitation represent local and regional atmospheric transportation by perfluorinated alkyl substances? Environ. Int. 55, 25-32.

Tomy, G.T., Tittlemlier, S.A., Palace, V.P., Budakowski, W.R., Braekevelt, E., Brinkworth, L., Friesen, K., 2004. Biotransformation of N-ethyl perfluorooctanesulfonamide by rainbow trout (Oncorhynchus mykiss) liver microsomes. Environ. Sci. Technol. 38 (3), $758-762$.

UNEP, 2009. The conference of the parties 4 of the Stockholm Convention (COP-4) in Geneva placed perfluorooctane sulfonate and perfluorooctane sulfonyl fluoride (PFOS and PFOSF) in Annex B. http://chmpopsint/Convention/Pressrelease/ COP4Geneva9May2009/tabid/542/language/en-US/Defaultaspx (accessed 14.08.16).

USEPA, 2006. 2010/2015 PFOA Stewardship Program. https://www.epagov/assessing-andmanaging-chemicals-under-tsca/fact-sheet-20102015-pfoa-stewardship-program (accessed 14.08.16)

USEPA, 2009. Provisional health advisories for perfluorooctanoic acid (PFOA) and perfluorooctyl sulfonate (PFOS). https://www.epagov/sites/production/files/201509/documents/pfoa-pfos-provisional.pdf (accessed 14.08.16).

USEPA, 2014. Emerging contaminants-perfluorooctane sulfonate (PFOS) and perfluorooctanoic acid (PFOA). https://nepisepagov/Exe/ZyPDFcgi/P100EIVCPDF? Dockey $=$ P100EIVCPDF (accessed 14.08.16).

Wang, B., Cao, M., Zhu, H., Chen, J., Wang, L., Liu, G., Gu, X., Lu, X., 2013. Distribution of perfluorinated compounds in surface water from Hanjiang River in Wuhan, China. Chemosphere 93 (3), 468-473.

Wang, P., Lu, Y., Wang, T., Meng, J., Li, Q., Zhu, Z., Sun, Y., Wang, R., Giesy, J.P., 2016a. Shifts in production of perfluoroalkyl acids affect emissions and concentrations in the environment of the Xiaoqing River Basin, China. J. Hazard. Mater. 307, 55-63.

Wang, P., Lu, Y., Wang, T., Zhu, Z., Li, Q., Meng, J., Su, H., Johnson, A.C., Sweetman, A.J., 2016b. Coupled production and emission of short chain perfluoroalkyl acids from a fast developing fluorochemical industry: evidence from yearly and seasonal monitoring in Daling River Basin, China. Environ. Pollut. 218, 1234-1244.

Wang, T., Khim, J.S., Chen, C., Naile, J.E., Lu, Y., Kannan, K., Park, J., Luo, W., Jiao, W., Hu, W., Giesy, J.P., 2012. Perfluorinated compounds in surface waters from Northern China: comparison to level of industrialization. Environ. Int. 42, $37-46$

Wang, T., Wang, P., Meng, J., Liu, S., Lu, Y., Khim, J.S., Giesy, J.P., 2015. A review of sources, multimedia distribution and health risks of perfluoroalkyl acids (PFAAs) in China. Chemosphere 129, 87-99.

Wang, T., Wang, Y., Liao, C., Cai, Y., Jiang, G., 2009. Perspectives on the inclusion of perfluorooctane sulfonate into the Stockholm Convention on persistent organic pollutants 1. Environ. Sci. Technol. 43 (14), 5171-5175.

Wang, Z., Cousins, I.T., Scheringer, M., Buck, R.C., Hungerbuhler, K., 2014a. Global emission inventories for C4-C14 perfluoroalkyl carboxylic acid (PFCA) homologues from 1951 to 2030, part I: production and emissions from quantifiable sources. Environ. Int. 70, $62-75$.

Wang, Z., Cousins, I.T., Scheringer, M., Buck, R.C., Hungerbuhler, K., 2014b. Global emission inventories for C4-C14 perfluoroalkyl carboxylic acid (PFCA) homologues from 1951 to 2030, part II: the remaining pieces of the puzzle. Environ. Int. 69, 166-176.

Wang, P., Lu, Y., Wang, T., Fu, Y., Zhu, Z., Liu, S., Xie, S., Xiao, Y., Giesy, J.P., 2014c. Occurrence and transport of 17 perfluoroalkyl acids in 12 coastal rivers in south Bohai coastal region of China with concentrated fluoropolymer facilities. Environ. Pollut. 190, 115-122.

Wu, K., Xu, X., Peng, L., Liu, J., Guo, Y., Huo, X., 2012. Association between maternal exposure to perfluorooctanoic acid (PFOA) from electronic waste recycling and neonatal health outcomes. Environ. Int. 48, 1-8.

Xiao, F., Simcik, M.F., Gulliver, J.S., 2012a. Perfluoroalkyl acids in urban stormwater runoff: influence of land use. Water Res. 46 (20), 6601-6608.

Xiao, F., Halbach, T.R., Simcik, M.F., Gulliver, J.S., 2012b. Input characterization of perfluoroalkyl substances in wastewater treatment plants: source discrimination by exploratory data analysis. Water Res. 46 (9), 3101-3109.

Xiao, F., Simcik, M.F., Halbach, T.R., Gulliver, J.S., 2015. Perfluorooctane sulfonate (PFOS) and perfluorooctanoate (PFOA) in soils and groundwater of a US metropolitan area: migration and implications for human exposure. Water Res. 72, 64-74.

Xie, S., Wang, T., Liu, S., Jones, K.C., Sweetman, A.J., Lu, Y., 2013a. Industrial source identification and emission estimation of perfluorooctane sulfonate in China. Environ. Int. $52,1-8$.

Xie, S., Lu, Y., Wang, T., Liu, S., Jones, K., Sweetman, A., 2013b. Estimation of PFOS emission from domestic sources in the eastern coastal region of China. Environ. Int. 59, 336-343.

Yan, H., Cousins, I.T., Zhang, C., Zhou, Q., 2015. Perfluoroalkyl acids in municipal landfill leachates from China: occurrence, fate during leachate treatment and potential impact on groundwater. Sci. Total Environ. 524, 23-31.

Yi, L.I., Zhu, J., Geng, H., 2012. Health risks of aqueous film forming foam extinguishing agent in a polluted soil site. J. Environ. Health 29 (12), 1096-1100.

Young, C.J., Furdui, V.I., Franklin, J., Koerner, R.M., Muir, D.C., Mabury, S.A., 2007. Perfluorinated acids in arctic snow: new evidence for atmospheric formation. Environ. Sci. Technol. 41 (10), 3455-3461.

Zareitalabad, P., Siemens, J., Hamer, M., Amelung, W., 2013. Perfluorooctanoic acid (PFOA) and perfluorooctanesulfonic acid (PFOS) in surface waters, sediments, soils and wastewater-a review on concentrations and distribution coefficients. Chemosphere 91 (6), 725-732.

Zhang, C., Peng, Y., Niu, X., Ning, K., 2014. Determination of perfluoroalkyl substances in municipal landfill leachates from Beijing, China. Asian J. Chem. 26 (13), 3833. 
Zhang, L., Liu, J., Hu, J., Liu, C., Guo, W., Wang, Q., Wang, H., 2012. The inventory of sources, environmental releases and risk assessment for perfluorooctane sulfonate in China. Environ. Pollut. 165, 193-198.

Zhang, W., Zhang, Y., Taniyasu, S., Yeung, L.W., Lam, P.K., Wang, J., Li, X., Yamashita, N., Dai, J., 2013. Distribution and fate of perfluoroalkyl substances in municipal wastewater treatment plants in economically developed areas of China. Environ. Pollut. 176, 10-17.
Zhao, L., Zhu, L., Zhao, S., Ma, X., 2016. Sequestration and bioavailability of perfluoroalkyl acids (PFAAs) in soils: implications for their underestimated risk. Sci. Total Environ. $572,169-176$.

Zhou, Z., Liang, Y., Shi, Y., Xu, L., Cai, Y., 2013. Occurrence and transport of perfluoroalkyl acids (PFAAs), including short-chain PFAAs in Tangxun Lake, China. Environ. Sci. Technol. 47 (16), 9249-9257. 